\title{
Embajadores comunitarios: sembrando liderazgo, donde más se necesita
}

\author{
Luis Germán Mena \\ Civitas Venezuela, Venezuela
}

\section{Resumen}

Se describe la experiencia sobre el impacto que han generado un grupo de jóvenes emprendedores "embajadores comunitarios" en la zona más vulnerable de Venezuela y considerado el sector popular más grande de América Latina: Petare. Bajo la premisa "sembrar liderazgo, donde más se necesita" se sistematizan las acciones de estos embajadores de la Escuela Fe y Alegría María Inmaculada, ubicada en el sector El Carmen, Petare. En este artículo, se comparte el proceso vivido por un grupo de jóvenes preocupados por su escuela y aplicando las herramientas de liderazgo, investigación, vocería, oratoria, debate, argumentación y la metodología del aprendizaje servicio; conceptualizan la campaña educativa "Todos queremos pasarla bien". En resumen, se plantea el punto de partida de esta experiencia, metodología y resultados sobre cómo estos embajadores mejoraron las creencias de los estudiantes, docentes, padres y actores claves de la comunidad ante el acoso escolar.

\section{Palabras clave}

Liderazgo juvenil; empoderamiento; bullying; participación; ciudadanía .

Fecha de recepción: 15/VIII/2014

Fecha de aceptación: 14/V/2015 


\title{
Community ambassadors: sowing leadership, where most needed
}

\begin{abstract}
Systematize the experience of the impact generated a group of young entrepreneurs "community ambassadors" in the most vulnerable area of Venezuela and considered the greatest popular sector in Latin America is described. Under the premise "leadership planting where it is most needed" the actions of these ambassadors of Fe y Alegría School Mary Immaculate, located in the El Carmen, Petare. In this article, the process experienced by a group of young people concerned about their school and applying the tools of leadership, research, spokesperson, speech, debate, argument and methodology of service learning is shared; conceptualized the educational campaign "We all want a good time." In summary, the starting point of this experience, methodology and results on how these ambassadors improved beliefs of students, teachers, parents and community stakeholders to bullying arises.
\end{abstract}

\section{Keywords}

Youth leadership, empowerment, bullying, participation, citizenship 


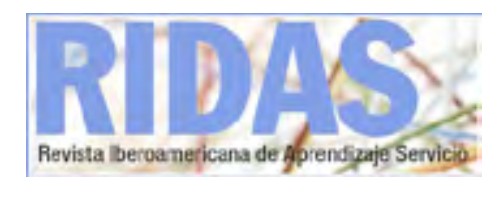

\section{Introducción}

"Sembrar liderazgo, donde más se necesita" frase que sistematiza las acciones de los embajadores comunitarios de la Escuela Fe y Alegría María Inmaculada, ubicada en el sector El Carmen Petare, Venezuela. Es una retrospectiva de un año de transformaciones, donde han cambiado las carencias usuales del entorno escolar por negociación, oratoria y resolución pacífica de conflictos; utilizando la metodología del aprendizaje servicio. Se describe cómo un grupo de jóvenes preocupados por su escuela, conceptualizan la campaña educativa "Todos queremos pasarla bien".

Esta experiencia fue abordada de manera multidisciplinaria por la Asociación Civil Civitas Venezuela, la Universidad Metropolitana de Caracas y la Fundación Embajadores Comunitarios. Este abordaje fue realizado de manera integral, con jóvenes cuyas edades oscilan entre 10 y 19 años de edad, mediante estrategias de empoderamiento juvenil, que facilitó que los jóvenes lograran cubrir sus necesidades asociadas al desarrollo de su identidad, identificación con un rol y formación de vínculos con la escuela de manera satisfactoria.

Los actores claves de esta experiencia son los embajadores comunitarios, jóvenes que han participado en el modelo Naciones Unidas y que decidieron poner en práctica todos sus conocimientos y experiencias en pro de crear un espacio dentro de la escuela llamado embajadas como una instancia extra-cátedra de participación, articulación e integración juvenil donde se reúnen para diagnosticar los problemas más relevantes de la comunidad y, lo más importante, diseñan y ejecutan proyectos para contribuir su solución.

En resumen, se plantea el punto de partida de esta experiencia, metodología y resultados sobre cómo estos embajadores mejoraron las creencias de los estudiantes, docentes, padres y actores claves de la comunidad ante el bullying. 


\section{Aproximación teórica de la experiencia}

Para contextualizar teóricamente esta experiencia y aplicando las herramientas de modelo Naciones Unidas, los embajadores reflexionaron sobre ¿Qué es el empoderamiento? $Y$ llegaron al consenso que es un proceso intencional centrado en la comunidad, que involucra respeto mutuo, pensamiento crítico, empatía y participación en grupos a través del cual personas que carecen de acceso a recursos valiosos logran obtener mayor acceso y control sobre esos recursos.

Del mismo modo les permitió plantearse como dilema ¿cómo lograrlo? a) fortaleciendo relación aprendizaje-vida; b) fomentando la toma de decisiones; c) manteniendo una estructura de trabajo y d) reforzando positivamente.

Con las herramientas del modelo Naciones Unidas: Iiderazgo, investigación, vocería, oratoria, debate y argumentación los embajadores comunitarios realizaron un diagnóstico; para determinar de qué manera se podría disminuir el acoso escolar; se plantearon un proyecto de aprendizaje servicio el diseño de una campaña educativa dentro y fuera de la escuela "Todos queremos pasarla bien".

\section{Metodología}

Para lograr mayor participación de los jóvenes de la escuela, se plantearon conformar cuatro equipos de trabajo: Ansuz, nombre del símbolo vikingo de la creatividad; Inguz, nombre del símbolo vikingo de la acción; Dagaz, nombre del símbolo vikingo de la perseverancia y Kenaz, nombre del símbolo vikingo de la confianza. Esto permitió un trabajo armónico entre los embajadores.

Se estructuró el desarrollo de la experiencia en función de las siguientes fases:

La primera "una revisión desde mi ser" ¿quién soy yo?. Esta fase 
culminó con la declaración "un salario emocional". Basado en la satisfacción con lo que hago, con las relaciones que construyo y con las habilidades que desarrollo.

La segunda fase fue "las bitácoras de trabajo" Desde octubre del 2013 hasta julio del 2014, se establecieron sesiones de trabajo con la finalidad de cumplir con todos objetivos propuestos, durante el año escolar.

La tercera fase, denominada "manos a la obra" representó la conceptualización y desarrollo de las actividades de la campaña educativa "Todos queremos pasarla bien" dentro y fuera de la escuela.

La última fase "pensando, actuando y proponiendo" consistió en jornadas de reflexión al finalizar cada actividad con todos los actores involucrados para evaluar e identificar las lecciones aprendidas de la experiencia.

De manera transversal, las alianzas institucionales asumieron el acompañamiento desde el experimentar, observar, conceptualizar y aplicar.

Lás áreas y contenidos trabajados fueron: 1) Cómo se diseña una campaña educativa, 2) Determinar la imagen, el manifiesto y las estrategias de difusión, 3 ) Estrategias de sostenibilidad de las actividades vinculadas con la campaña educativa y 4 ) La articulación de las unidades curriculares con los contenidos de la campaña.

Las actividades realizadas se enuncian a continuación:

- Sensibilizar y concienciar a la comunidad educativa del colegio María Inmaculada sobre la problemática del acoso escolar

- Fomentar el respeto entre los actores de la comunidad educativa.

- Fortalecer el equipo Embajadas 
- Identificar e involucrar personas, alianzas, grupos y organizaciones que puedan apoyar la ejecución del proyecto.

- Desarrollar las actividades vinculadas con la campaña: Actividad interactiva, durante los espacios libres en la escuela, encuentros deportivos, encuentros familiares, formación de docentes en herramientas de abordaje del bullying, festival "Todos queremos pasarla bien"

\section{Resultados}

Por mencionar algunos aspectos significativos de esta experiencia, los estudiantes han logrado sensibilizar a toda la comunidad educativa, se evidencia $95 \%$ de disminución de situaciones de acoso expresada por los estudiantes, docentes y familiares; y algo muy importante todos la quieren pasarla bien. Fue una campaña inclusiva. La integración les permitió conocerse, y desde este conocimiento, dejaron de afectar a los demás de forma negativa. Todas las actividades desarrolladas, se ejecutaron en base a dos premisas: comunicar alegría, optimismo y felicidad y ejecutar ideas inclusivas.

Por último, los impactos causados en los jóvenes fueron la sensibilización con la problemática del acoso escolar, el abordaje de sus problemas de manera integral y el asumir responsabilidades hacia la campaña educativa. Y en relación a la comunidad se destaca el reconocimiento del trabajo de los embajadores en la comunidad, la incorporación en las actividades comunitarias del lema "todos queremos pasarla bien" y la importancia de trabajar en equipo. 